Loyalitas Kreativitas

Aldi Masyarakat Kreatif
P-ISSN 2722-2101, E-ISSN 2722-4201

Program Studi Ekonomi Manajemen Universitas Pamulang

Jurnal LOKABMAS Kreatif Vol.02,No.01,Maret 2021 Hal. 55-63

Email:jurnalkreatif.manajemen@gmail.com

\title{
NARKOBA DALAM KAJIAN AGAMA DAN HUKUM SERTA DAMPAKNYA TERHADAP SOSIAL DAN EKONOMI
}

\author{
Wiwik Hasbiyah AN,Khotimatus Sadiyah, Haryono,Sugeng Samiyono,R.Mohd Zamzami, \\ Dosen Ekonomi Fakultas Ekonomi Universitas Pamulang \\ Email dosen02232@unpam.ac.id, dosen00968@unpam.ac.id, dosen00961@unpam.ac.id \\ dosen01271@unpam.ac.id , dosen01386@unpam.ac.id
}

\begin{abstract}
ABSTRAK
Pengabdian masyarakat ini berjudul "Narkoba dalam Kajian Agama dan Hukum Serta Dampaknya Terhadap Sosial dan Ekonomi" yang dilaksanakan di yayasan AlKamilah Sawangan Depok.

Tujuan pengabdian ini adalah memberikan penyuluhan dan pendampingan terhadap Santriwan santriwati berkaitan dengan pencegahan dan peyebaran tentang bahaya narkoba dalam sosial ekonomi dengan harapan dengan adanya penyuluhan tersebut pada Santriwan dan santriwati mampu memebentengi diri dengan pengetahuan Agama yang kuat dan pengetahuan hukum negara sehingga mampu memilah milih temen dengan cara pergaulan yang baik yang membawa kebaikan bagi diri khususnya dan bagi masyarakat umumnya di yayasan Alkamilah untuk meraih keberkahan dalam kehidupan santriwan santriwati di yayasan Alkamilah Serua depok Jawabarat.

Metode pelaksanaan pengabdian ini adalah dengan penyuluhan dan pendampingan melalui rangkaian kegiatan identifikasi, pengkajian serta proses belajar yang terencana dengan 3 tahapan yaitu 1) Pengumpulan data, dengan memberikan data wawancara kepada Santriwan santriwati tentang pemahaman narkoba dalam sudut kajian agama dan hukum 2). Pelatihan Pemasaran syariah dengan memberikan penyuluhan kepada Santriwan santriwati di yayasan Al-kamilah. 3) Memberikan pendampingan Pelatihan tentang pengetahuan Agama dan Hukum terhadap obat terlarang yaitu narkoba. Untuk mendukung hal itu diperlukan sebuah rencana kegiatan diantaranya adalah tahap persiapan yaitu dengan menyiapkan semua peralatan yang dibutuhkan untuk melaksanan kegiatan pkm, studi literatur dan melakukan koordinasi dengan instansi lembaga yayasan terkait serta ketua yayasan khususnya. Tahap penentuan lokasi, yaitu dengan melakukan kunjungan ke lokasi. Tahap Perancangan implemnetasi dan pengawasan melalui pelatihan pemasaran syariah yang dilakukan oleh 5 orang dosen universitas pamulang fakultas ekonomi kepada santriwan santriwati di yayasan Alkamilah sawangan Depok

Kesimpulan dari pengabdian ini adalah peserta pengabdian sangat antusias terhadap pelatihan, hal ini ditunjukan dengan banyaknya antusiasme pertanyaan tentang narkoba, baik pencegahan,peyebarandan bahaya narkoba dalam sosial ekonomi.
\end{abstract}

\section{Kata Kunci: Narkoba, Agama, Hukum, Sosial, Ekonomi}


Loyalitas Kreativitas

Aldi Masyarakat Kreatif
P-ISSN 2722-2101, E-ISSN 2722-4201

Program Studi Ekonomi Manajemen Universitas Pamulang

Jurnal LOKABMAS Kreatif Vol.02,No.01,Maret 2021 Hal. 55-63

Email:jurnalkreatif.manajemen@gmail.com

\begin{abstract}
ABSTRAC
This community service entitled "Drugs in the Study of Religion and Law and Their Impact on Social and Economic Affairs" was carried out at the AlKamilah Sawangan Depok foundation.

The aim of this service is to provide counseling and assistance to Santriwan santriwati related to the prevention and dissemination of the dangers of drugs in the socioeconomy with the hope that this counseling will be able to fortify themselves with strong religious knowledge and knowledge of state law so that they are able to sort out their friends by a good way of association that brings goodness for oneself in particular and for the general public at the Alkamilah foundation to achieve blessings in the life of the santriwati santriwati at the Alkamilah Serua foundation, Depok Answerarat.

The method of implementing this service is through counseling and assistance through a series of identification activities, assessment and a planned learning process with 3 stages, namely 1) Data collection, by providing interview data to Santriwan santriwati about understanding drugs in the perspective of religious and legal studies 2). Sharia marketing training by providing counseling to Santriwan santriwati at the Al-kamilah foundation. 3) Providing training assistance on religious and legal knowledge on illegal drugs, namely drugs. To support this, an activity plan is needed, including the preparation stage, namely by preparing all the equipment needed to carry out PKM activities, studying literature and coordinating with related foundation agencies and the head of the foundation in particular. The location determination stage, namely by making a site visit. Design stage implementation and supervision through sharia marketing training conducted by 5 lecturers at the Pamulang University Faculty of Economics to santriwan santriwati at the Alkamilah sawangan Depok foundation
\end{abstract}

The conclusion of this service is that the participants are very enthusiastic about the training, this is shown by the many enthusiasm questions about drugs, both prevention, distribution and the dangers of drugs in the socio-economic situation.

\title{
Keywords: Drugs, Religion, Law, Social, Economy
}

\section{PENDAHULUAN}

Narkoba yang merupakan akronim dari narkotika, psikotropik,a dan bahan adiktif lainnya menjadi kekhawatiran tersendiri bagi masa depan bangsa Indonesia. Sebab, narkoba sangat berbahaya bagi kesehatan akal dan dapat merusak kerja otak.Islam telah memberikan ramburambu dengan tegas terkait dengan segala macam yang bisa dikonsumsi 
Loyalitas Kreativitas

Aldi Masyarakat Kreatif
P-ISSN 2722-2101, E-ISSN 2722-4201

Program Studi Ekonomi Manajemen Universitas

Pamulang

Jurnal LOKABMAS Kreatif Vol.02,No.01,Maret 2021

Hal. 55-63

Email:jurnalkreatif.manajemen@gmail.com termasuk narkoba. Narkoba ini, kendati tidak disebutkan secara gamblang di dalam Al-Qur'an, tetapi karena dampak buruk yang dihasilkan lebih banyak, maka bisa dipastikan narkoba dilarang untuk dikonsumsi.

Ibnu Taimiyah bahkan sempat memberikan fatwa haram terkait narkoba secara tegas. Beliau berkata, "Narkoba sama seperti zat yang memabukkan lainnya. Diharamkan sesuai kesepakatan para ulama dan setiap zat yang dapat menghilangkan akal, haram untuk dikonsumsi walau tidak memabukkan.

Di Indonesia, pencandu narkoba ini perkembangannya semakin pesat. Para pencandu narkoba itu pada umumnya berusia antara 11 sampai 24 tahun. Artinya usia tersebut ialah usia produktif atau usia pelajar.Pada awalnya, pelajar yang mengonsumsi narkoba biasanya diawali dengan perkenalannya dengan rokok. Karena kebiasaan merokok ini sepertinya sudah menjadi hal yang wajar di kalangan pelajar saat ini. Dari kebiasaan inilah, pergaulan terus meningkat, apalagi ketika pelajar tersebut bergabung ke dalam lingkungan orang-orang yang sudah menjadi pencandu narkoba. Awalnya mencoba, lalu kemudian mengalami ketergantungan.Bagai dua sisi mata uang narkoba menjadi zat yang bisa memberikan manfaat dan juga merusak kesehatan. Seperti yang sudah diketahui, ada beberapa jenis obat-obatan yang termasuk ke dalam jenis narkoba yang digunakan untuk proses penyembuhan karena efeknya yang bisa menenangkan. Namun jika dipakai dalam dosis yang berlebih, bisa menyebabkan

kecanduan.

Penyalahgunaan ini mulanya karena si pemakai merasakan efek yang menyenangkan.Dari sinilah muncul keinginan untuk terus menggunakan agar bisa mendapatkan ketenangan yang bersifat halusinasi. Meski dampak narkoba sudah diketahui oleh banyak orang, tetap saja tidak mengurangi jumlah pemakainya, sehingga bahaya dan dampak narkoba atau narkotika dan obat-obatan pada kehidupan dan kesehatan pecandu dan keluarganya semakin meresahkan. Dari sinilah perlu adanya sosialisasi tentang narkoba bagi remaja-remaja khususnya santriwan dan santriwati di yayasan Al kamilah.

Saat ini, telah berdiri sebuah yayasan sosial di Jl. Serua Raya No.3, Serua, Kec. Bojongsari, Kota Depok. Yayasan ini bernama AlKamilah, yayasan ini berdiri sejak 30 Oktober 2012 yang telah mampu menampung 30 anak asuh di asrama depok. Sedangkan 50 anak diantaranya berada Kebumen, Purwakarta, dan Banten. Melihat permasalahan tersebut, sangatlah penting memberikan penyuluhan tentang narkoba kepada masyarakat khususnya santriwan santriwatidi yayasan Alkamilah, sekaligus sebagai wujud Tri Darma Perguruan Tinggi, Fakultas Ekonomi S1 UNPAM, maka diselenggarakanlah kegiatan pengabdian kepada masyarakat dengan judul "Narkoba dalam kajian agama dan hukum Serta Dampaknya Terhadap Sosial dan Ekonomi”

\section{RUMUSAN MASALAH}




\section{Loyalitas Kreativitas Aldi Masyarakat Kreatif}

P-ISSN 2722-2101, E-ISSN 2722-4201

Program Studi Ekonomi Manajemen Universitas

Pamulang

Jurnal LOKABMAS Kreatif Vol.02,No.01,Maret 2021

Hal. 55-63

Email:jurnalkreatif.manajemen@gmail.com
Dengan memperhatikan latar belakang yang telah dipaparkan diatas perumusan masalah pada PKM ini adalah :

1) Bagaimana memberikan Penyuluhan Narkoba Dalam Sudut Kajian Agama Dan Hukum Pada Santriwan dan Santriwati di Yayasan Al-kamilah?

2) Bagaimana memberikan Penyuluhan pada santriwan santriwati Tentang Dampak Narkoba Terhadap Sosial Dan Ekonomi?

3) Bagaimana Pencegahan Terhadap Penyebaran Dan penyalahgunaan Narkoba dikalangan Genersi Muda?

\section{TUJUAN PELAKSANAAN}

Tujuan yang dicapai dalam pengabdian ini yaitu :

1) Membantu Santriwan dan Santriwati di yayasan Alkamilah dalam memahami Narkoba dalam sudut Kajian agama dan hukum.

2) Memberikan Wawasan kepada Santriwan Santriwati di yayasan Alkamilah tentang Bagaimana Dampak Bahaya Narkoba Terhadap Sosial dan Ekonomi.

3) Memberikan Penyuluhan Tentang pencegahan Terhadap Penyebaran dan Penyalahgunaan Narkoba di Kalangan Generasi Muda.

\section{TINJAUAN PUSTAKA}

Dalam Islam, narkotika dan obatobatan terlarang, seperti ganja, heroin, dan lainnya disebut dengan istilah mukhaddirat. Hukum mengonsumsi benda-benda ini, apa pun bentuknya, telah disepakati keharamannya oleh para ulama. Tak ada satu pun ulama yang menyelisihkan keharaman mukahddirat tersebut. Para ulama mengqiyaskan hukum mukhaddirat pada hukum khamar. Mereka berdalil dengan hadis yang dikemukakan Umar bin Khattab RA, "Khamar adalah segala sesuatu yang menutup akal." (HR Bukhari Muslim). Jadi, narkotika masuk dalam cakupan definisi khamar seperti yang disebutkan Umar bin Khattab RA.

Dr Yusuf Qardhawi dalam kumpulan fatwa kontemporernya menerangkan, akibat yang ditimbulkan pemakai narkotika sama saja dengan orang yang mabuk karena khamar. Sering kali terjadi kecelakaan lalu lintas sebagai akibat dari pengaruh benda-benda memabukkan itu. Hal ini bukti hilangnya kesadaran seseorang akibat narkotika. Lebih lanjut, Qardhawi menerangkan, kalau barang-barang mukhaddirat tersebut tidak dimasukkan dalam kategori khamar atau memabukkan, ia tetap haram dari segi melemahkan (menjadikan loyo). Banyak orang yang memang tidak mabuk mengonsumsi narkoba. Namun, tubuh mereka akan menjadi lemah dan memiliki efek halusinasi. 


\section{Loyalitas Kreativitas Aldi Masyarakat Kreatif}

P-ISSN 2722-2101, E-ISSN 2722-4201

Program Studi Ekonomi Manajemen Universitas

Pamulang

Jurnal LOKABMAS Kreatif Vol.02,No.01,Maret 2021

Hal. 55-63

Email:jurnalkreatif.manajemen@gmail.com
Imam Abu Daud meriwayatkan dari Ummu Salamah mengatakan, "Rasulullah SAW melarang segala sesuatu yang memabukkan dan melemahkan (menjadikan lemah)." (HR Abu Daud). Dalam hadis ini disebut dengan istilah al-mufattir, yaitu sesuatu yang menjadikan tubuh loyo atau tidak bertenaga. Larangan dalam hadis ini untuk mengharamkan karena itulah hukum asal bagi suatu larangan. Selain itu, juga disebabkan dirangkaikannya antara yang memabukkan yang telah disepakati keharamannya dan mufattir. Alasan selanjutnya, jika benda-benda tersebut seandainya tidak termasuk dalam kategori memabukkan dan melemahkan, ia termasuk dalam jenis khabaits (sesuatu yang buruk) dan membahayakan.

Islam mengharamkan memakan sesuatu yang buruk dan membahayakan, sebagaimana firman Allah SWT, "...dan menghalalkan bagi mereka segala yang baik dan mengharamkan bagi mereka segala yang buruk." (QS al-A'raf [7]: 157). Rasulullah SAW juga bersabda, "Tidak boleh membahayakan diri sendiri dan tidak boleh memberi bahaya (mudarat) kepada orang lain." (HR Ahmad, Ibnu Majah). Segala sesuatu yang membahayakan manusia adalah haram. Inilah yang ditegaskan dalam Alquran, "Dan janganlah kamu membunuh dirimu; sesungguhnya Allah adalah Maha Penyayang kepadamu." (QS an-Nisa' [4]: 29). Ayat lainnya, "Dan janganlah kamu menjatuhkan dirimu sendiri ke dalam kebinasaan." (QS alBaqarah [2]: 195).

\section{METODE PELAKSANAAN}

Melihat permasalahan yang dihadapi maka langkah-langkah yang dilakukan untuk mencapai tujuan dan sasaran kegiatan ini adalah:

\section{Tahap Persiapan}

Tahap persiapan yang dilakukan meliputi :

1) Survei awal, Pada tahap ini dilakukan survei lokasi Yayasan Alkamilah di Desa Serua, Kec. Bojongsari Kab. Depok JawaBarat.

2) Observasi. Setelah survei maka ditentukan pelaksanaan dan sasaran peserta kegiatan

3) Rapat Koordinasi Tim. Pada tahap ini rapat mengenai pembagian tugas, membuat jadwal pelaksanaan, mulai dari persiapan, pelaksanaan, sampai evaluasi dan penyusunan laporan.

\section{Tahap Evaluasi}

Tahap evaluasi merupakan penilaian setelah rangkaian kegiatan dilakukan oleh pelaksana sesuai dengan jadwal yang telah ditentukan. Evaluasi ini bisa berupa perbaikan atau saran untuk pelaksanaan kegiatan lebih baik lagi dan kelanjutan menjadi binaan kampus. 
Loyalitas Kreativitas

Aldi Masyarakat Kreatif
P-ISSN 2722-2101, E-ISSN 2722-4201

Program Studi Ekonomi Manajemen Universitas

Pamulang

Jurnal LOKABMAS Kreatif Vol.02,No.01,Maret 2021

Hal. 55-63

Email:jurnalkreatif.manajemen@gmail.com a. Partisipasi Mitra dalam

Pelaksanaan Program

Partisipasi mitra dalam pelaksanaan program PKM ini sangat kooperatif dengan memberikan ijin kepada tim untuk melaksanaankan pengabdian desa binaan kampus, memberikan keterangan baik berupa informasi atau data-data yang dibutuhkan sampai rencana pelaksanaan berupa kegiatan pelatihan/pendampingan

nantinya.

\section{b. Realisasi Pemecahan Masalah}

Realisasi pemecahan masalah dalam Pengabdian Kepada Santriwati Santriwan yayasan Al Kamilah ini, menghasilkan beberapa hal yang dapat di laksanakan oleh para dosen antara lain:

1) Untuk pengabdian selanjutnya adalah membuat rumah baca tentang buku buku kesyariahan dan tahfis quran bagi Santriwan Santriwati dalam upaya meningkatkan kecerdasan dan ketaqwaan agar mudah terimplementasi nya pemahaman tentang perilaku akhlakul karimah yang mampu membentengi diri dari pengaruh negatif pada santriwan santriwati di yayasan Alkamilah.

2) Melaksanakan pendampingan dengan memberikan penyuluhan terhadap Santriwan Santrwati dalam upaya untuk Pencegahan dan penyebaran obat erlarang bahaya dan dampaknya tersebut di yayasan Alkamilah serua depok JawaBarat.

\section{c. Khalayak Sasaran}

Khalayak sasaran dalam Pengabdian Kepada Msyarakat ini adalah seluruh Santriwan Santriwati di Yayasan Alkamilah Serua depok Jawa barat.

Dengan adanya Penyuluhan tersebut diharapkan nantinya Santriwan dan santriwati mampu memebentengi diri dengan pengetahuan Agama yang kuat dan pengetahuan hukum negara sehingga memiliki pergaulan yang baik yang membawa kebaikan dan keberkahan bagi diri khususnya dan bagi masyarakat umumnya di yayasan Alkamilah Serua depok Jawabarat.

\section{HASIL DAN PEMBAHASAN}

Berikut ini adalah hasil dan pembahasan dan kegiatan pengabdian masyarakat yang telah dilakukan pada Sabtu-Selasa/ 12 Desember s/d 15 Desember 2020 adalah:

\begin{tabular}{|c|c|c|c|c|}
\hline No & Waktu & Susunan Acara & \multicolumn{2}{|c|}{\begin{tabular}{|l} 
Pemateri/ \\
Penanggung Jawab
\end{tabular}} \\
\hline 1 & $09.00-09.30$ & Pembukaan dan Pengenalan & \multicolumn{2}{|l|}{ Semua dosen } \\
\hline 2 & $09.30-09.45$ & Pembacaan Ayat Suci Al Qur'an & \multicolumn{2}{|c|}{ Santri Al-Kamilah } \\
\hline 3 & $09.45-10.00$ & Sambutan Ketua Yayasan & \multicolumn{2}{|c|}{ Badruddin, S.Ag., M.M } \\
\hline 4 & \multirow{2}{*}{$10.00-10.15$} & \multirow{2}{*}{ Sambutan Panitia } & Sugeng & \\
\hline & & & \\
\hline \multirow[b]{2}{*}{5} & \multirow[b]{2}{*}{$10.15-11.00$} & \multirow{2}{*}{$\begin{array}{l}\text { Materi "Narkoba dalam kajian } \\
\text { Agama" }\end{array}$} & \begin{tabular}{|l} 
Samiyono, SH.,MH \\
Wiwik
\end{tabular} & \\
\hline & & & \multicolumn{2}{|c|}{ Hasbiyah,SHI,MA } \\
\hline 6 & $11.00-11.45$ & $\begin{array}{l}\text { Materi "Narkoba Dalam Kajian } \\
\text { Hukum" }\end{array}$ & \multicolumn{2}{|c|}{ Haryono, MM.,MH } \\
\hline \multirow[t]{2}{*}{7} & $11.45-14.00$ & Sholat Dzuhur dan Makan Siang & Panitia & \\
\hline & & Diskusi dan tanya jawab & MC: & \\
\hline 8 & $14.00-16.45$ & & Khotimatus & Sadiyah \\
\hline & & & SSI.,M.M & \\
\hline 11 & $16.45-17.00$ & Doa dan Penutup & Ust. & Badruddin \\
\hline & & & S.Ag.,M.M & \\
\hline
\end{tabular}


Loyalitas Kreativitas

Aldi Masyarakat Kreatif
P-ISSN 2722-2101, E-ISSN 2722-4201

Program Studi Ekonomi Manajemen Universitas

Pamulang

Jurnal LOKABMAS Kreatif Vol.02,No.01,Maret 2021

Hal. 55-63

Email:jurnalkreatif.manajemen@gmail.com
1. Acara dibuka dengan

Pembukaan PKM Dengan

pembacaan Ummul AlQuraan

bersama sama, dimana pada saat ini diberikan berbagai macam sambutan, baik dari pihak Yayasan Alkamilah maupun dari pihak UNPAM. Setelah itu, acara dilanjutkan didalam ruangan dengan memberikan pembekalan materi kepada para peserta PKM yang terdiri dari para guru yayasan dan Santriwan Santriwati Yayasan Al-Kamilah Depok JawaBarat.

2. Materi yang pertama diberikan oleh narasumber adalah tentang Narkoba dalam Kajian Agama Yaitu tentag larangan mengkonsumsi obat terlarang tersebut karena narkoba itu hukumnya sama dengan khamr yaitu haram , dan juga karena bisa membahayakan diri khususnya umumnya pada masyarakat disekitarnya. Islam mengharamkan memakan sesuatu yang buruk dan membahayakan, sebagaimana firman Allah SWT, "...dan menghalalkan bagi mereka segala yang baik dan mengharamkan bagi mereka segala yang buruk." (QS al-A'raf [7]: 157).

Rasulullah SAW juga bersabda, "Tidak boleh membahayakan diri sendiri dan tidak boleh memberi bahaya (mudarat) kepada orang lain." (HR Ahmad, Ibnu Majah).

3. Materi selanjutnya yang diutarakan oleh narasumber yang kedua yaitu Narkoba dalam kajian Hukum dan dampaknya terhadap Sosial Ekonomi Yaitu Psikotropika adalah zat atau obat, baik alamiah maupun sintetis bukan narkotika, yang berkhasiat psikoaktif melalui pengaruh selektif pada susunan saraf pusat yang menyebabkan perubahan pada aktivitas mental dan perilaku (Undang-Undang No. 5/1997). Terdapat empat golongan psikotropika menurut undangundang tersebut, tetapi setelah diundangkannya UU No. 35 tahun 2009 tentang narkotika, maka psikotropika golongan Idan II dimasukkan kedalam golongan narkotika.

4. Setelah semua materi diutarakan, maka dilakukan quis dan permainanpermainan dengan memberikan pertanyaan pertanyaan dengan memberikan hadiah kuis baik yang bertanya maupun yang menjawab. Tujuannya adalah untuk menguji pemahaman peserta mengenai materi yang sudah diberikan.

\section{KESIMPULAN DAN SARAN}

\section{Kesimpulan} adalah:

Kesimpulan dari pengabdian ini

1.Mengadakan Pengabdian Kepada Santriwan santriwati dalam pendampingan lanjutan dengan penyuluhan tentang narkoba dalam kajian agama dan hukum serta dampaknya terhadap sosial dan ekonomi.

2.Pada Pengabdian Kepada Masyarakat selanjutnya Memberikan kontribusi dengan membikin rumah baca berhubugan dengan kajian agama dan hukum tentang bahaya narkoba dan dampaknya terhadap sosial ekonomi.

3.Pada Pengabdian Masyarakat selanjutnya melaksanakan 
Email:jurnalkreatif.manajemen@gmail.com

pendampingan pada per kelompok yaitu putra santriwan dan kelompok putri santriwati dalam upaya mewujudkan santri yang bisa membentengin diri dari pengaruh luar dengan pembekalan agar mempunyai akhlakul Karimah sehingga mampu bergaul dengan pergaulan yang baik manfaatnya untuk diri sendiri khususnya umumnya untuk masyarakat.

\section{Saran}

Agar kedepannya nanti kami peserta PKM dan yayasan bisa mewujudkan Rumah baca yang berhubungan dengan Kajian Agama dan Hukum Positif tentang Bahaya Narkoba dan dampaknya terhadap sosial Ekonomi guna memberikan kemudahan fasilitas santriwan santriwati untuk bisa lebih mudah mengakses pengetahuan tentang kajian Agama dan Hukum Positif untuk Santriwan santriwati agar bisa memilah milih mana yang baik dalam pergaulan dan tidak baik agar tidak berdampak pada dirinya khususnya dan pada masyarakat sekitarnya dan bisa membentengi diri dengan akhlakul Karimah.

\section{DAFTAR PUSTAKA}

Al-Qur'an Al-Karim dan Terjemahan, Lembaga Percetakan Al-Qur'an Raja Fahd

Atmasamita, Romli, 2001, Tindak Pidana Narkotika Trans Nasional Dalam

Hawari, D. 2002, Agama (Islam) Menanggulangi NAZA (Narkotika,
Alkohol, \& Zat Adiktif), Yogyakarta: Dana Bhakti Prima Yasa

Media Indonesia, 2006. Kompilasi Peraturan Perundang-Undangan tentang Narkoba (KPPUN), Jakarta, kencana.

Mustofa, Mohammad. 2007. Kriminologi: Kajian Sosiologi terhadap Kriminalitas, Perilaku

Menyimpang dan Pelanggaran Hukum, Depok: Fisip UI.

Mardani. H. 2008, Penyalahgunaan Narkoba Dalam Perspektif Hukum Islam Dan Hukum Pidana Nasional, Jakarta, PT. Raja Grafindo Persada

Sistem Hukum Indonesia, Bandung, Citra Aditya Bakti A. Soedjono, 2000, Patologi Sosial, Bandung, Alumni

Sitanggang, B.A, 1999,Pendidikan PencegahanPenyalahgunaan Narkotika, Jakarta, Karya Utama

Waresniwiro, M, 1997, Narkotika Berbahaya, Jakarta, Mitra Bintibmas

UU No. 5 Tahun 1997 tentang Psikotropika

UU No. 22 Tahun 1997 tentang Narkotika

\section{DOKUMENTASIFOTO} KEGIATAN 
Loyalitas Kreativitas Aldi Masyarakat Kreatif
P-ISSN 2722-2101, E-ISSN 2722-4201

Program Studi Ekonomi Manajemen Universitas Pamulang

Jurnal LOKABMAS Kreatif Vol.02,No.01,Maret 2021 Hal. 55-63

Email:jurnalkreatif.manajemen@gmail.com

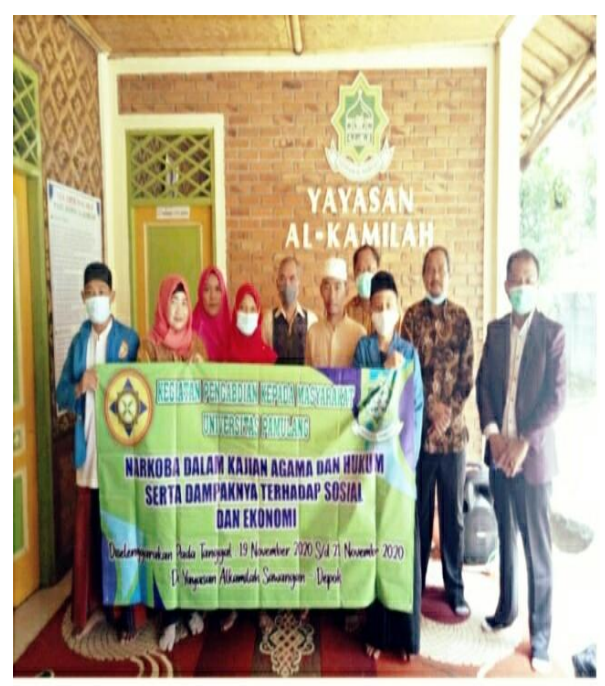

Foto bersama dosen dan perangkat yayasan Al Kamilah

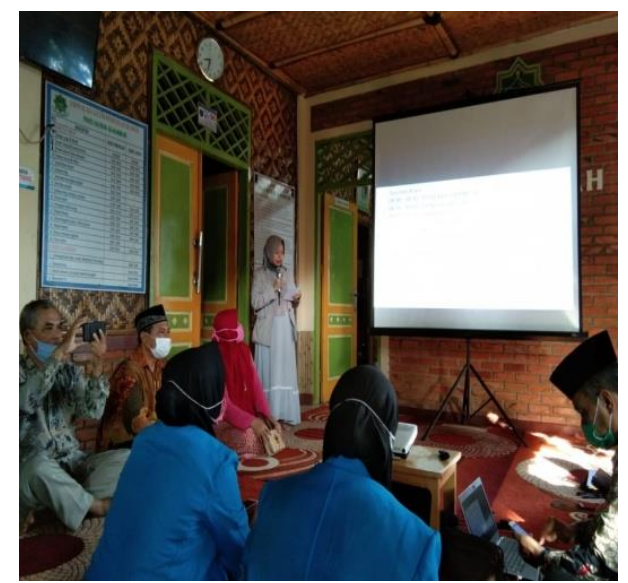

Foto pembukaan Acara oleh Mc

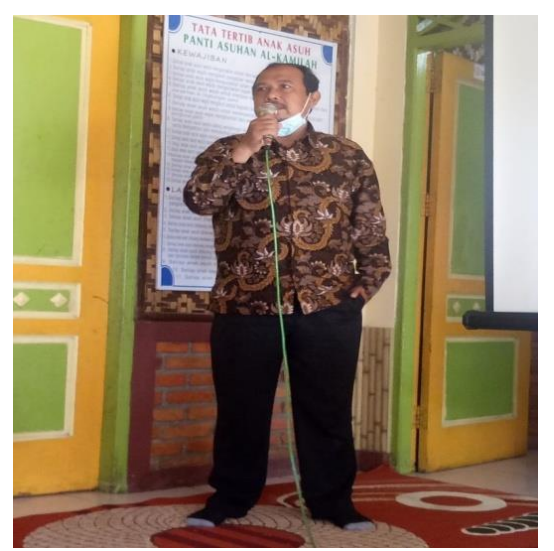

Foto Sambutan Ketua PKM
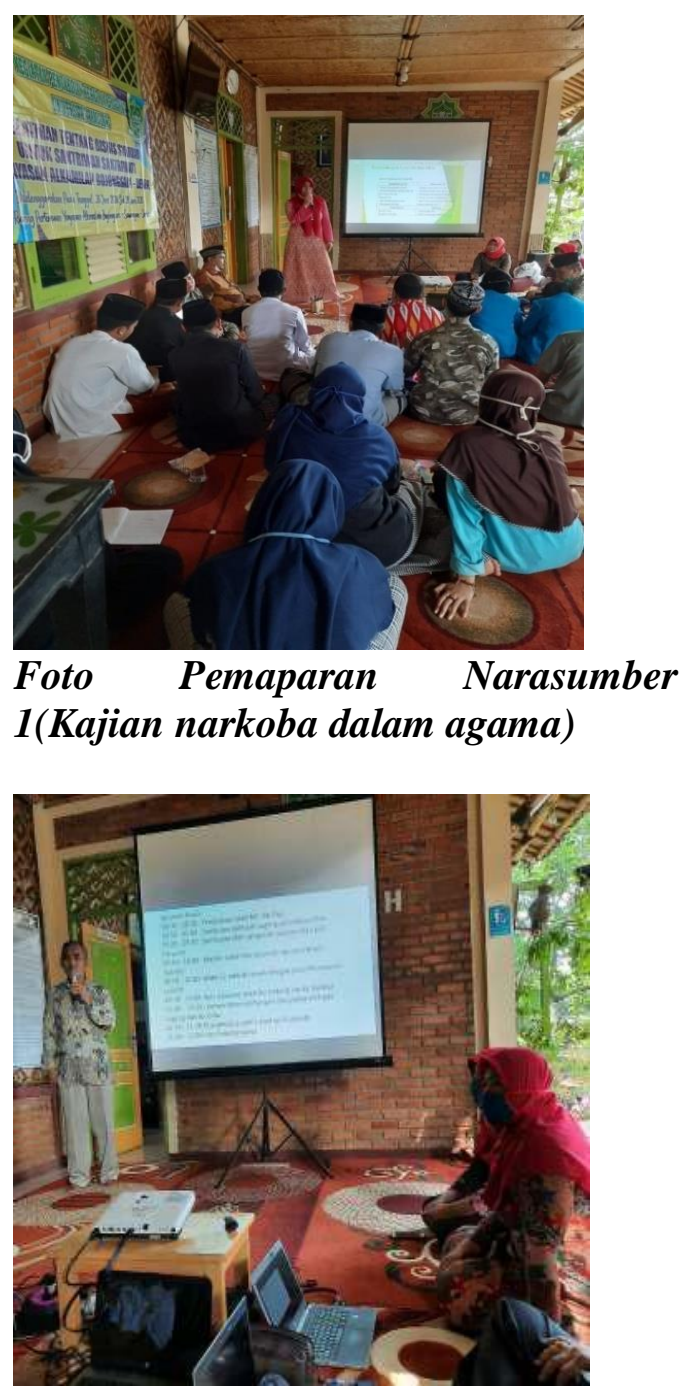

Foto Pemaparan Narasumber 2(Narkoba dalam kajian hukum dan UU Negara) 